\title{
Epidemiological characteristics of 778 patients who underwent surgical drainage of chronic subdural hematomas in Brasília, Brazil
}

\author{
Emerson B Sousa ${ }^{1,2^{*}}$, Laise FS Brandão ${ }^{3}$, Cléciton B Tavares ${ }^{1}$, Igor BC Borges ${ }^{1}$, Nelson G Freire Neto ${ }^{1,2}$ \\ and Iruena M Kessler ${ }^{2}$
}

\begin{abstract}
Background: Chronic subdural hematomas (CSDHs) are common in neurosurgical practice. There are no publications that report large series of the epidemiological characteristics of this pathology in Brazil. The purpose is to describe a large series of surgical cases and analyze the epidemiological and clinical characteristics.

Methods: We retrospectively analyzed patients with CSDH admitted into Neurosurgical Services at the Hospital de Base do Distrito Federal, Brasília, Brazil from 2006 to 2011. Age, sex, clinical feature, etiology, surgical procedure, side, clinical outcome, and recurrence were reviewed. Statistical tests were used to analyze data, and $P<0.05$ was considered statistically significant.

Results: The series included 778 patients. There were 643 (82.6\%) male patients with a mean age of $64.3 \pm 15.9$ (range, 14-93) years. The principal symptom was headache (58.9\%). The most frequent origin was a fall (282 cases, 36.2\%), but the origin remained unclear in 281 (36.1\%) patients. Mild head injury occurred in 540 (69.4\%) cases. Burr holes with drainage were used as the surgical procedure in 96.5\% patients, and 687 (88.3\%) patients had a positive outcome. Mortality was $0 \%$. Recurrence was observed in 42 cases.

Conclusions: The occurrence of CSDHs is more common in elderly men. Treatment with burr holes and drainage is a simple and safe method for treatment. In our experience, CSDH presents decreased morbidity and mortality.
\end{abstract}

Keywords: Chronic subdural hematoma, Outcome, Surgery, Recurrence, Burr hole, Craniotomy, Epidemiology, Brazil

\section{Background}

A chronic subdural hematoma $(\mathrm{CSDH})$ is a slowly growing encapsulated collection of blood and its breakdown products located between the dura mater and the arachnoid. A CSDH is the result of tearing in the bridging veins, usually caused by minor trauma, and its risk factors include atrophy and coagulopathy in the brain [1,2]. Radiologically, a CSDH has been defined, based on the density discovered in the computed tomography (CT) scan, as a hypodense subdural hematoma, compared with parenchyma, and it presents 21 days after trauma [1].

\footnotetext{
* Correspondence: emerson_brand@hotmail.com

'Service of Neurosurgery at the Hospital de Base do Distrito Federal, Brasília, Brazil

${ }^{2}$ Department of Medicine, University of Brasília, Brasília, Brazil

Full list of author information is available at the end of the article
}

A CSDH is one of the most common conditions encountered in neurosurgical practice. The common occurrence of CSDH in older patients causes a variety of diagnostic and therapeutic challenges because of frequently described nonspecific symptoms and accompanying diseases [1]. The incidence of CSDH increases greatly with age, and its occurrence ranges from approximately 3.4 per 100,000 in patients younger than 65 years of age to $8-58$ per 100,000 in those older than 65 years $[2,3]$.

The, presentation, management, and prognosis of CSDHs are well-documented, but there are few publications that report the epidemiological characteristics of this pathology in Brazilian neurosurgery [4-6]. A series of surgical CSDH cases from our institution will be presented, and the epidemiological and clinical characteristics, causes, surgical results, and recurrence rate will be described.

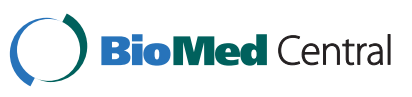




\section{Methods}

We retrospectively analyzed all patients admitted to Neurosurgical Services at the Hospital de Base do Distrito Federal, Brasília, Brazil with a CSDH between January 2006 and December 2011. In all cases, the diagnosis of CSDH was made using the cranial CT scan of the patient performed before the surgical procedure that showed a crescent-shaped hypodense or isodense hemispheric collection of blood layered over the cerebral convexity, independent of knowledge of an occurrence of a traumatic injury (Figure 1). A surgical evacuation was performed when the hematoma's thickness was larger than $10 \mathrm{~mm}$, when focal symptoms were present, or when there were significant changes in neurologic status in patients with CSDH of any thickness. Anticoagulant/ antithrombotic drugs were stopped if used by a patient. After a normal international normalized ration was confirmed, the surgery was performed. In case of an emergency procedure and coagulopathy, anticoagulant status was reversed with vitamin $\mathrm{K}$ and fresh frozen plasma.

The neurosurgical staff on duty selected the type of surgical procedure (burr hole with closed-system drainage or craniotomy). The surgery was performed under general anesthesia by creating one burr hole of approximately $10 \mathrm{~mm}$ in diameter in the side of the location of the hematoma. After exposing the dura mater and the outer membrane of the hematoma, the collection of blood was evacuated under its own tension, and irrigation was performed using physiological saline solution until clear fluid came out. When the subdural space allowed, a closed subdural drainage system, without any negative pressure, was placed and subcutaneously tunneled for at least $5 \mathrm{~cm}$. Subdural drainage was continued up to $48 \mathrm{~h}$ after surgery, during which time, the patient was supine in bed. During the craniotomy, a piece of bone was removed and the largest portion of the brain was exposed. After exposing the dura mater and the outer membrane of the hematoma, only the outer membrane was removed. After evacuation of the hematoma, the piece of bone was replaced and fixed to the skull. Surgical hemostasis was performed with monopolar /bipolar cautery and oxidized regenerated cellulose (Surgicel $^{\mathrm{R}}$, Johnson \& Johnson, Arlington, TX, USA).

After the surgery, the patients routinely received seizure prophylaxis with $15 \mathrm{mg} / \mathrm{Kg}$ of phenytoin by slow IV, followed by $100 \mathrm{mg}$ IV every $8 / 8 \mathrm{~h}$, and prophylactic antibiotic with cefazolin $1 \mathrm{~g}$ IV every $8 / 8 \mathrm{~h}$ for $48 \mathrm{~h}$. The patients stayed in the post-anesthesia recovery room and in the neurosurgical ward. A cranial CT was only performed in patients with clinical complications. Subcutaneous injection of $40 \mathrm{mg}$ of enoxaparin was used after $24 \mathrm{~h}$ of surgical procedures for prophylaxis against deep vein thrombosis during the patient's stay in hospital.

We reviewed age, sex, the presenting signs and symptoms, Glasgow Coma Scale (GCS), origin, type of surgical procedure, side of the skull in which the hematoma occurred, days of hospitalization, Glasgow Outcome Scale (GOS) at discharge, and the recurrence of $\mathrm{CSDH}$ for each patient. CSDH recurrence was determined when the clinical status did not improve after the operation or new neurological symptoms occurred with reaccumulation of a subdural blood collection, as seen on a CT scan. There was no follow-up of patients after discharge from hospital.

All data were analyzed using the commercially available statistical software package SPSS 20.0 (SPSS $^{\circledR}$, Chicago, IL, USA). Continuous distributed variables were separately compared using the student's $t$-test, and they were reported as mean \pm standard deviations (SD). Proportions were compared with chi-square and Fisher's

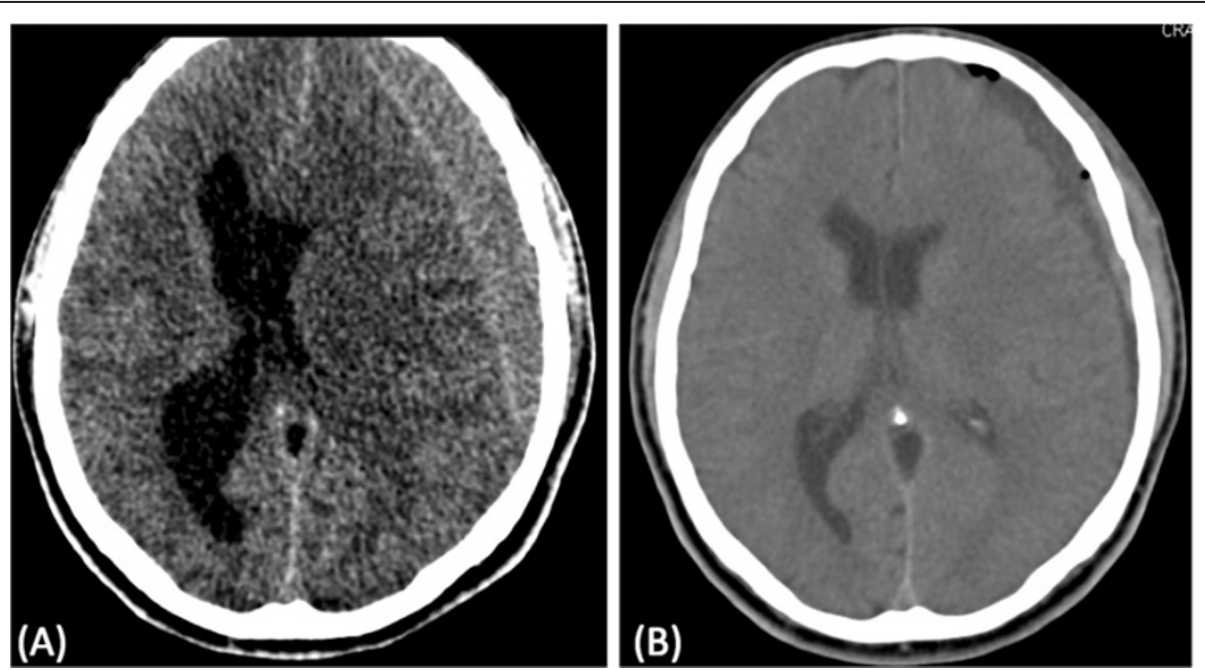

Figure 1 Computerized tomography scans (CT). (A) chronic subdural hematoma; (B) CT-scan $24 \mathrm{~h}$ after surgery. 
exact test, and they were presented as percentages. $\mathrm{P}<0.05$ was considered statistically significant. The study protocol was approved by the institute's committee on human research (Comitê de Ética em Pesquisa da Secretaria de Saúde do Distrito Federal, protocol 138/2012).

\section{Results}

The sample consisted of 778 patients. The annual incidence of $\mathrm{CSDH}$ is illustrated in Figure 2. Of the cases, 643 were male, and 135 were female (ratio 4.8:1). The age range was 14-93 years, the mean age for all patients was $64.3 \pm 15.9$ years, and the mean ages for male and female patients were $63.0 \pm 14.9$ and $70.0 \pm 18.8$ years, respectively $(\mathrm{P}<0.001$; Figure 3$)$. An age 65 years or older was associated with a more frequent incidence of CSDH: $56.8 \%(n=442)$ of the patients were older than 65 years, whereas $43.2 \%(n=336)$ were younger. In patients younger than 65 years, $87.5 \%$ were male, and $12.5 \%$ were female; in patients 65 years of age and older, $79 \%$ were men, and $21 \%$ were women $(\mathrm{P}<0.005)$. Table 1 presents the main characteristics of the population in study, and Figure 4 shows the distribution of sex based on age.

The origin of the CSDH was determined in 497 patients $(63.9 \%)$ and remained unclear in 281 patients (36.1\%). Of the determined cases, 470 had suffered a previous head injury, and 27 patients had coagulopathy or used an anticoagulant/antiaggregant therapy without a history of trauma associated with the treatment. The causes of the head injuries were a fall (282 cases), traffic accident (74 cases), aggression (35 cases), or other accidents (79 cases). Falls represented $60.7 \%$ (82 of 135 cases) of the causes of $\mathrm{CSDH}$ in female patients, but they accounted for only $31.1 \%$ (200 of 643 cases) in the male patients $(\mathrm{P}<0.001)$. Falls also represented the most frequent origin of trauma in patients aged 65 years or older (154 cases) and in patients younger than 65 years

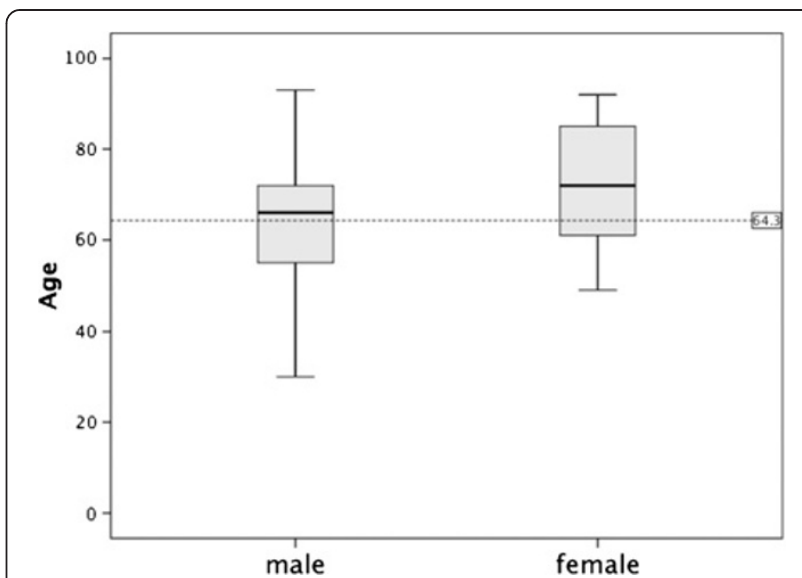

Figure 3 Box-and-whisker plot of age as a function of sex of patients with CSDH. The lines demarcate the median and interquartile range, and the whiskers indicate the upper and lower limits of the data. The dashed line demarcates the mean age (in years) of 778 patients who underwent CSDH operations in Neurosurgical Services at the Hospital de Base do Distrito Federal, Brasília, Brazil.

(96 cases; $\mathrm{P}>0.05$ ). Traffic accidents and aggression were significantly more frequent in patients younger than 65 years of age $(\mathrm{P}<0.001$ and $\mathrm{P}<0.01$, respectively).

The most frequent symptom of $\mathrm{CSDH}$ was headache (458 cases; $58.9 \%$ ), which was followed by altered behavior (272 cases; $35 \%$ ) and hemiparesis (271 cases; 34.8\%). The frequency of the presenting symptoms is shown in Table 2. The leading symptom for the age and the sex was headache, hemiparesis and behavioral disturbance. Altered behavior was significantly more frequent in patients with 65 years of age or older than in younger patients (38.7\% versus 22\%; $\mathrm{P}<0.001)$. Mild head injury (GCS 15-14 points) occurred in 540 patients (69.4\%), moderate head injury (GCS $13-9$ points) occurred in

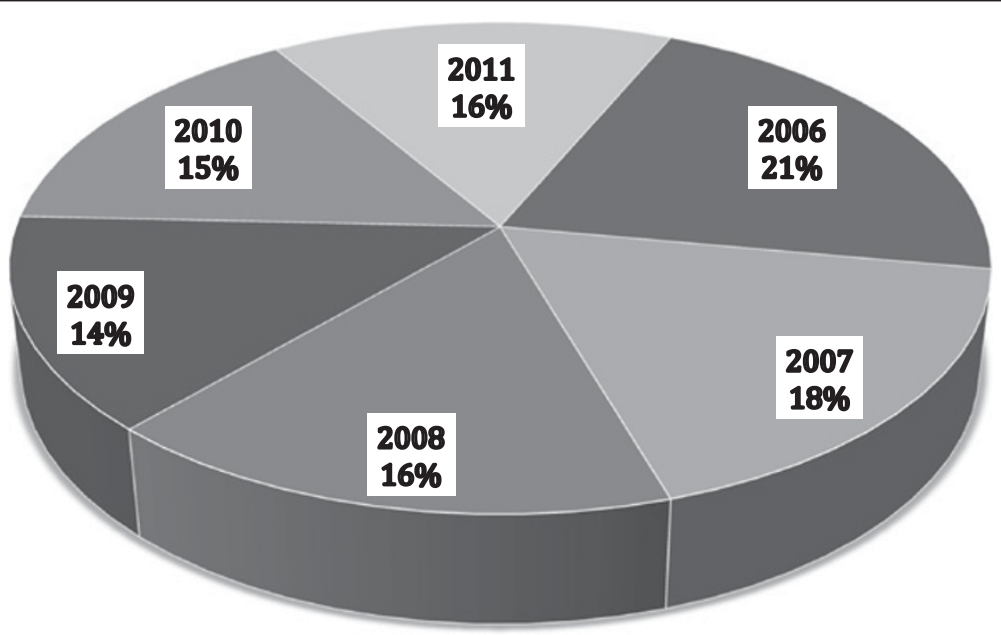

Figure 2 Annual incidence of 778 patients with CSDH. 
Table 1 Characteristics of $\mathbf{7 7 8}$ patients with CSDH

\begin{tabular}{ll}
\hline Sex & \\
\hline Male (\%) & $643(82.6 \%)$ \\
$\quad$ Female (\%) & $135(17.4 \%)$ \\
Age in years (mean \pm SD) and range & $64.3 \pm 15.9(14-93)$ \\
$\quad<65$ years (\%) & $336(43.2 \%)$ \\
$\quad \geq 65$ years (\%) & $442(56.8 \%)$ \\
Median (IQR) GCS on admission & $14(13-15)$ \\
GCS (\%) & \\
15-14 & $540(69.4 \%)$ \\
13-9 & $192(24.7 \%)$ \\
8-3 & $30(3.9 \%)$ \\
Convexity hematoma (\%) & \\
$\quad$ Left & $293(37.7 \%)$ \\
$\quad$ Right & $311(40.0 \%)$ \\
Bilateral & $174(22.3 \%)$ \\
Origin & \\
Fall & $282(36.2 \%)$ \\
Traffic accident & $74(9.5 \%)$ \\
Aggression & $35(4.5 \%)$ \\
Other accidents & $79(10.1 \%)$ \\
Coagulopathy or anticoagulant/ & $27(3.5 \%)$ \\
Untiaggregant therapy & \\
\hline
\end{tabular}

Values shown are mean \pm standard deviations (SD), unless otherwise specified, and percentages, where indicated. GCS = Glasgow coma scale; $I Q R=$ Interquartile range.

192 patients (24.7\%), and severe head injury (GCS 8-3 points) occurred in 30 patients (3.9\%).

The postoperative results are shown in Table 3. The CSDH was on the right side of the brain in 293 patients (37.7\%), the left side in 311 (40.0\%), and bilateral in the remaining $174(22.3 \%)$ cases. Bilateral CSDH occurred significantly more often in younger patients than in older patients $(26.5 \%$ versus $19.2 \%$; $\mathrm{P}<0.05)$ and in male patients more than female patients $(26.3 \%$ versus $5.2 \%$; $\mathrm{P}<0.001)$. The surgical procedures undertaken in patients with CSDH were burr holes with drainage in $96.5 \%$ of cases (751 patients) and craniotomy in 3.5\% of cases (27 patients). A total of 42 (5.4\%) patients required further surgery to remove a recurring CSDH, and one case underwent a third operation. The average time of the second intervention was approximately 4 weeks with a $71.4 \%$ recurrence rate within 3 months.

Of the patients, $687(88.3 \%)$ had a positive outcome (GOS 5). Patients with severe brain injuries upon admission had poor outcomes (GOS 3-2) compared with patients with mild and moderate brain injuries $(50.0 \%$, $0.9 \%$, and $7.8 \%$, respectively; $\mathrm{P}<0.001)$. Postoperative mortality was $0 \%$.

The mean stay in the Department of Neurosurgery was $6.53 \pm 7.7$ days, ranging from 3 to 58 days (median, 4 days); $82 \%$ were discharged within 1 week, $9.8 \%$ within 2 weeks, and the remaining patients after 2 weeks. The average number of days of hospitalization for patients with GCS 8-3 (10.6 \pm 9.8 days) was statistically greater than patients with GCS 15-14 and GCS 13-9 (6.3 \pm 8.0 and $6.85 \pm 7.3$, respectively; $\mathrm{P}<0.02)$. Patients with poor outcomes (GOS 3-2) had a greater mean of days hospitalized than patients with good recoveries $(24.5 \pm 18.5$ and $5.7 \pm 5.6$ days, respectively; $\mathrm{P}<0.001$; Figure 5).

\section{Discussion}

In 1657, J. J. Wepfer was the first to describe a CSDH, and in 1857, Virchow detailed the pathophysiology of this hematoma, naming it pachymeningitis haemorrhagica interna [1,7]. Many authors have since demonstrated that lesions are easily treated with minimal morbidity or mortality.

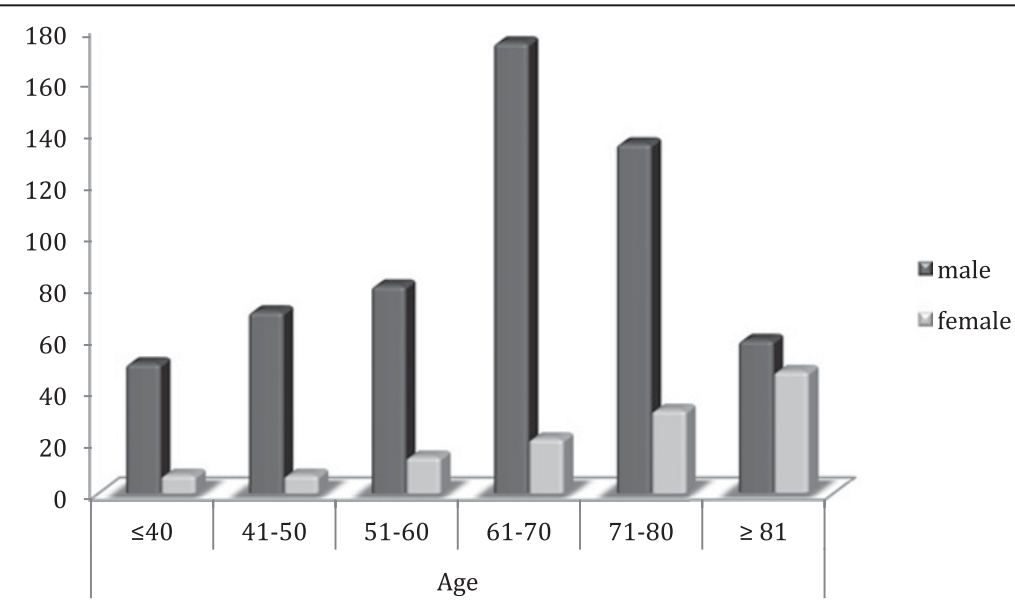

Figure 4 Bar graph of sex as a function of age for 778 patients with CSDH. 
Table 2 Symptoms of 778 patients with CSDH ${ }^{*}$

\begin{tabular}{ll}
\hline Headache & $458(58.9 \%)$ \\
Hemiparesis & $271(34.8 \%)$ \\
Cognitive disturbances & $176(22.6 \%)$ \\
Altered behavior & $272(35.0 \%)$ \\
Seizure & $20(2.6 \%)$ \\
\hline
\end{tabular}

Values are $\mathrm{n}(\%) .{ }^{*}$ More than one symptom per patient is possible.

CSDH occur in the dural border cell layer, located between the dura mater and the arachnoid. The dissection of these cell layers creates a subdural cavity [8]. Patients with extensive brain atrophy (elderly and alcoholics) or conditions resulting in intracranial hypotension (ventriculoperitoneal shunt) are vulnerable to developing CSDH [1,2]. Traversing veins are being increasingly stretched by the shrinking brain until only a minor additional force is sufficient to cause the rupture of the bridging veins and create the hematoma. This is followed by fibrin deposition, organization, enzymatic fibrinolysis, and liquefaction of the clot [1,2,9-11]. An inflammatory reaction occurs, and neomembranes (inner or visceral and outer or parietal membranes) are formatted with the growth of neocapillaries and enzymatic hyperfibrinolysis. CSDH tend to gradually enlarge because repeated micro-hemorrhage may lead to clinical signs and symptoms of increased intracranial pressure or compression brain structures [2,9-12].

The elderly and male preponderance of CSDH has already been described [1-3,13-15]. In the elderly, the brain weighs approximately 200 g less, which leads to an approximate $11 \%$ increase in extracerebral volume, allowing for greater movement of the brain [16]. Other factors explain why older people have a predisposition for trivial trauma. One rationale for male dominance could be that men generally have a greater exposure to injuries [15]. Studies show that male predominance

Table 3 Postoperative results of $\mathbf{7 7 8}$ patients with CSDH

\begin{tabular}{cl}
\hline Surgical procedures & \\
\hline Burr holes with drain & $751(96.5 \%)$ \\
Craniotomy & $27(3.5 \%)$ \\
Recurrence & $42(5.4 \%)$ \\
Within 3 months & $30(71.4 \%)$ \\
GOS, median (IQR) on admission* & $5(5-5)$ \\
5 & $687(88.3 \%)$ \\
4 & $56(7.2 \%)$ \\
3 & $35(4.5 \%)$ \\
Days hospitalized (mean \pm SD) & $6.53 \pm 7.7$ \\
\hline
\end{tabular}

Values shown are mean \pm standard deviations (SD), unless otherwise specified, and percentages, where indicated. GOS = Glasgow outcome scale $(5=\mathrm{Good}$ recovery; $4=$ Moderate disability with the ability to live independently; $3=$ Severe disability, unable to live independently; 2 = Vegetative state; $1=$ Dead); $I Q R=$ Interquartile range. *There were no patients with 1 or 2 GOS scores. diminishes with age $[3,9,15]$. This tendency to match the ratio between the sexes can be seen in our results also (Figure 3), and it can explain the greater life expectancy of women [3].

The history of trauma was acquired in $60.4 \%$ of patients. Among these, $282(60 \%)$ had a history of a fall (a trivial trauma). This is comparable to many studies that show an average of 56 to $77 \%$ of CSDH patients with a history of a fall [13-15,17]. In our results, traffic accidents and aggression were most frequent in patients with younger than 65 years of age, as well as in males; also, younger people generally have a greater exposure to injuries [15].

Chronic anticoagulation/antiaggregant therapy uses are also at increased risks for CSDH. Although the process is incompletely established, it has been suggested that asymptomatic "microbleeds" permit the development of a symptomatic hemorrhage [18]. These drugs, which are used in a large proportion of the elderly population, may add to the risk of CSDH by as much as 42.5 times [19]. Some studies report that patients initially taking anticoagulant medications have more risk of recurrence and longer stays in the hospital $[2,3,7,13,15,20]$. Our results show only $3.5 \%$ of all CSDH patients admitted were chronically anticoagulated/antiaggregated or had coagulopathy history. In one study, $41 \%$ of all CSDH patients admitted to a neurosurgical department in Switzerland were chronically anticoagulated [15]. Our data may be explained by incomplete medical records and by deficiencies in Brazilian public health in diagnosing pathologies requiring the chronic use of these drugs, as well as deficient distribution of these medicaments to the population.

Headache, hemiparesis, and behavioral disturbance were frequent symptoms in our study and in related articles $[3,5,13]$. In our series, behavioral disturbances were more frequent in patients 65 years of age or older compared with younger patients who frequently presented with increased intracranial pressure (headache). Gelabert-González et al. [3] and Asghar et al. [7] reported that the most common clinical characteristics in elderly patients were mental disorders.

Accepted management of CSDH (burr hole with or without closed-system drainage, twist-drill craniostomy, or craniotomy) is accompanied by recurrence rates of 4 to $26 \%[2,3,7,13,15]$. In our series, $96.5 \%$ of the surgical procedures undertaken in patients with $\mathrm{CSDH}$ were burr holes with closed-system drainage, and only $5.4 \%$ of patients experienced a recurrence. Craniotomy is the most invasive, encompassing the longest operating time and the greatest blood loss and remains with option in calcified or CSDH with numerous thick membranes [2]. Twist-drill craniostomy can be performed at the bedside in patients with multiple medical co-morbidities; however, there is a theoretical increased risk of contamination [21]. 

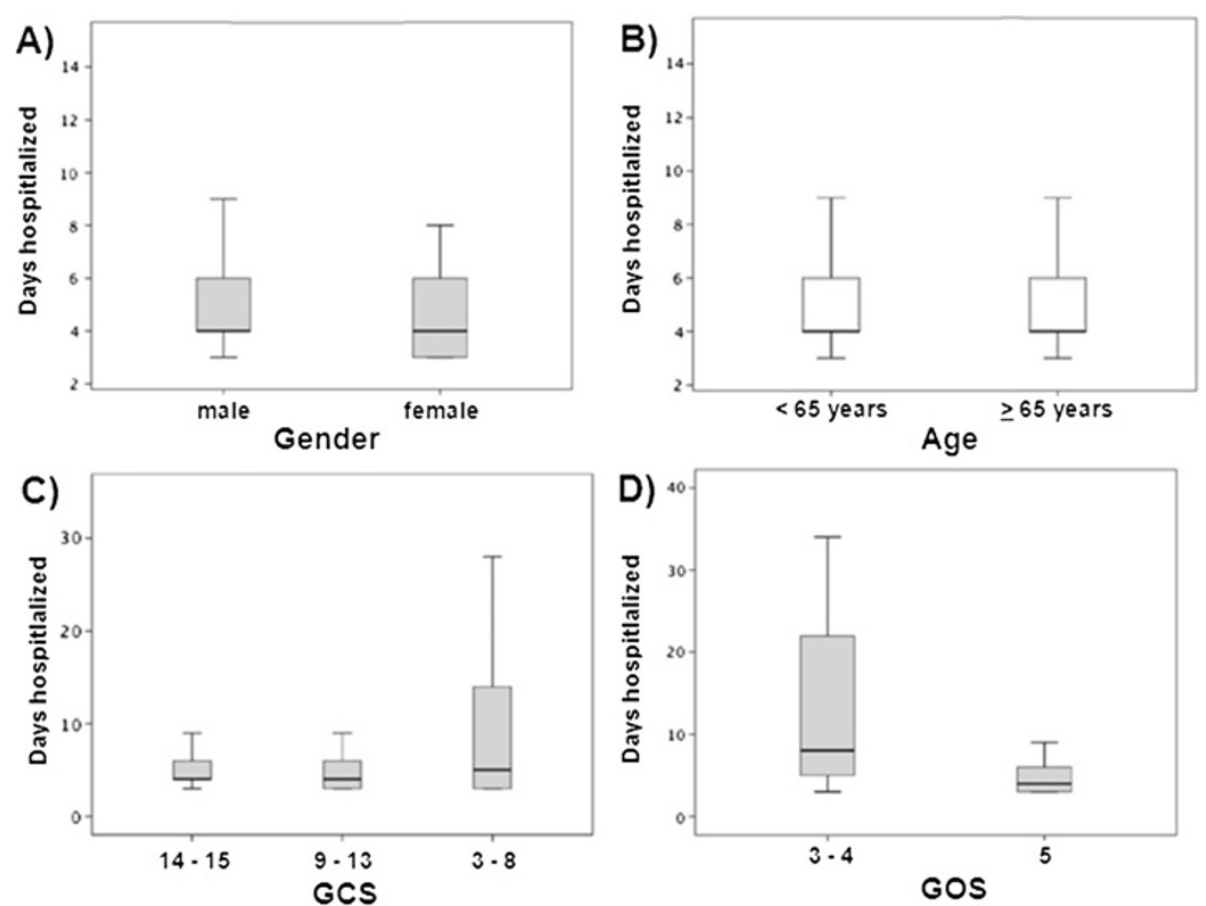

Figure 5 Box-and-whisker plot of days hospitalized for A) Gender B) Age C) GSC D) GOS of $\mathbf{7 7 8}$ patients with CSDH. The lines demarcate the median and interquartile range, and the whiskers indicate the upper and lower limits of the data of 778 patients who underwent CSDH operations in Neurosurgical Services at the Hospital de Base do Distrito Federal, Brasília, Brazil. GOS = Glasgow outcome scale $(5=$ Good recovery; 4 = Moderate disability with the ability to live independently; $3=$ Severe disability, unable to live independently; $2=$ Vegetative state; $1=$ Dead); GCS = Glasgow coma scale. *There were no patients with GOS scores of 1 or 2.

The most frequently used technique is burr-hole craniostomy with or without drainage [2]. The debate regarding the role of a drainage system in the surgical management of this pathology is ongoing. According to some reports, the installation of a drainage system helps brain expansion, decreasing the chance of recurrence [10]. However, the reported complications of a drainage system are significant, including hemorrhage, seizure induction, and infection $[2,3,10,11,20]$. Thus far, doubt persists about whether the installation of a drainage system is safer and more useful than irrigation without leaving a drainage system in place. Perhaps another explanation for the low recurrence rate of CSDH in our study is the lack of follow-up data of patients.

Positive functional results (score of 5 in GOS) have been shown in $72-93 \%$ of patients in several reports with the various types of surgical procedures, including twist-drill craniostomy, burr-hole craniostomy, and craniotomy $[21,22]$. Our patients also conform to this trend (88.3\%).

The mortality rate varies in a recent series from 0 to $13 \%[3,22]$, and in our series, the mortality rate was $0 \%$. Age, systemic complication, coagulopathy, and poor preoperative neurological state are contributory causes of postoperative death, functional outcome, and length of stay in the hospital $[2,3,10,11,20]$. This was evident in our study, as well.
Among the limitations of our study are the lack of personal history data, the tomographic imaging of the hematoma, and complications in patients who underwent operations without complete medical records. These limitations can be discussed in future research.

\section{Conclusion}

Chronic subdural hematomas are common neurosurgical problems associated with significant morbidity and mortality. In our series, headache and behavioral disturbance were the most frequent signs of CSDHs in elderly patients, and headache was the most frequent symptom in younger patients. A burr hole with closed-system drainage is a simple, safe, and efficient method for the treatment of CSDH, and it has a low occurrence of complications. In our experience, the worst prognostic factor for the outcome of CSDH in patients was the neurological condition at the time of surgery.

\section{Abbreviations}

CSDH: Chronic subdural hematoma; CT: Computerized tomography scan; GCS: Glasgow coma scale; GOS: Glasgow outcome scale; SD: Standard deviations; IQR: Interquartile range.

\section{Competing interests}

The authors declare that they have no competing interests.

\section{Authors' contributions}

EBS and LFSB were the key authors for the conception, design, coordination, and drafting of the manuscript, as well as the analysis and interpretation of 
the data. CBT and IBCB participated in the design and interpretation of the data and helped in drafting the manuscript. NGFN and IMK contributed substantively by revising the manuscript critically for intellectual content and participating in the interpretation of data and the revision of the manuscript. All authors read and approved the final manuscript.

\section{Author details}

${ }^{1}$ Service of Neurosurgery at the Hospital de Base do Distrito Federal, Brasilia, Brazil. 'Department of Medicine, University of Brasília, Brasília, Brazil. ${ }^{3}$ Department of Pós-graduação em Gerontologia, Universidade Católica de Brasília, Brasília, Brazil.

Received: 4 August 2012 Accepted: 13 February 2013

Published: 1 March 2013

\section{References}

1. Markwalder TM: Chronic subdural hematomas: a review. J Neurosurg 1981, 54:637-645.

2. Ducruet AF, Grobelny BT, Zacharia BE, Hickman ZL, DeRosa PL, Anderson K Sussman E, Carpenter A, Connolly ES Jr: The surgical management of chronic subdural hematoma. Neurosurg Rev 2012, 35(2):155-169.

3. Gelabert-González M, Iglesias-Pais M, García-Allut A, Martínez-Rumbo R: Chronic subdural haematoma: surgical treatment and outcome in 1000 cases. Clin Neurol Neurosurg 2005, 107(3):223-229.

4. Antunes Filho GD, Alliez J, Eva L, Reynier Y, Alliez B: Análise da cirurgia do hematoma subdural crônico em cem pacientes idosos [Analysis of the surgical treatment of chronic subdural hematoma in 100 elderly patients]. Ara Brasileiro Neurocirurgia 2006, 25(4):156-160.

5. Yasuda CL, Morita ME, Nishimori FY, Yasuda AM, Alves HL: Hematoma subdural crônico: estudo de 161 pacientes operados e a relação com alterações no coagulograma [Chronic subdural hematoma: study of 161 patients and the relationship with coagulation abnormalities]. Arq Neuropsiquiatr 2003, 61(4):1011-1014

6. Salomão JF, Leibinger RD, Lynch JC: Hematoma subdural crônico: tratamento cirúrgico e resultados em 96 pacientes [Chronic subdural hematoma: surgical treatment and results in 96 patients]. Arq Neuropsiquiatr 1990, 48(1):91-96.

7. Asghar M, Adhiyaman V, Greenway MW, Bhowmick BK, Bates A: Chronic subdural haematoma in the elderly: a North Wales experience. $J R$ Soc Med 2002, 95(6):290-292.

8. Haines DE, Harkey HL, al-Mefty O: The "subdural" space: a new look at an outdated concept. Neurosurgery 1993, 32:111-120.

9. Spallone A, Giuffrè R, Gagliardi FM, Vagnozzi R: Chronic subdural hematoma in extremely aged patients. Eur Neurol 1989, 29:18-22.

10. Gurelik M, Aslan A, Gurelik B, Ozum U, Karadag O, Kars HZ: A safe and effective method for treatment of chronic subdural haematoma. Can J Neurol Sci 2007, 34:84-87.

11. Markwalder TM, Steinsiepe KF, Rohner M, Reichenbach W, Markwalder $\mathrm{H}$ : The course of chronic subdural hematoma after burr-hole craniostomy and closed-system drainage. J Neurosurg 1981, 55(3):390-396.

12. Nomura S, Kashiwagi S, Fujisawa H, Ito H, Nakamura K: Characterization of local hyperfibrinolysis in chronic subdural hematomas by SDS-PAGE and immunoblot. J Neurosurg 1994, 81:910-913.

13. Mori $\mathrm{K}$, Maeda M: Surgical treatment of chronic subdural hematoma in 500 consecutive cases: clinical characteristics, surgical outcome, complications, and recurrence rate. Neurol Med Chir (Tokyo) 2001, 41:371-381.

14. Ramachandran R, Hegde T: Chronic subdural hematomas: causes of morbidity and mortality. Surg Neurol 2007, 67(4):367-373.

15. Baechli H, Nordmann A, Bucher HC, Gratzl O: Demographics and prevalent risk factors of chronic subdural haematoma: results of a large singlecenter cohort study. Neurosurg Rev 2004, 27(4):263-266.

16. Misra M, Salazar JL, Bloom DM: Subdural-peritoneal shunt: treatment for bilateral chronic subdural hematoma. Surg Neurol 1996, 46:378-383.

17. Talbot LA, Musiol RJ, Witham EK, Metter EJ: Falls in young, middle-aged and older community dwelling adults: perceived cause, environmental factors and injury. BMC Public Health 2005, 5:86.

18. Hanley JP: Warfarin reversal. J Clin Pathol 2004, 57(11):1132-1139.

19. Rust T, Kiemer N, Erasmus A: Chronic subdural haematomas and anticoagulation or anti-thrombotic therapy. J Clin Neurosci 2006, 13(8):823-827.
20. Nakajima H, Yasui T, Nishikawa M, Kishi H, Kan M: The role of postoperative patient posture in the recurrence of chronic subdural hematoma: a prospective randomized trial. Surg Neurol 2002, 58:385-387.

21. Williams GR, Baskaya MK, Menendez J, Polin R, Willis B, Nanda A: Burr-hole versus twist-drill drainage for the evacuation of chronic subdural haematoma: a comparison of clinical results. J Clin Neurosci 2001, 8(6):551-554.

22. Santarius T, Lawton R, Kirkpatrick PJ, Hutchinson PJ: The management of primary chronic subdural haematoma: a questionnaire survey of practice in the United Kingdom and the Republic of Ireland. Br J Neurosurg 2008, 22(4):529-534

doi:10.1186/1471-2482-13-5

Cite this article as: Sousa et al.: Epidemiological characteristics of 778

patients who underwent surgical drainage of chronic subdural hematomas in Brasília, Brazil. BMC Surgery 2013 13:5.

\section{Submit your next manuscript to BioMed Central and take full advantage of:}

- Convenient online submission

- Thorough peer review

- No space constraints or color figure charges

- Immediate publication on acceptance

- Inclusion in PubMed, CAS, Scopus and Google Scholar

- Research which is freely available for redistribution 